\title{
K PROBLEMATIKI PREVAJANJA AFRIŠKEGA EVROFONSKEGA ROMANA V SLOVENŠČINO
}

Ključne besede: afriški roman, prevajanje, Bahtin, postkolonialne študije

V romanu Ahmadouja Kouroume z zgovornim naslovom Monnè, outrages et défis med osrednjimi liki srečamo tolmača, ki v trenutku vdora kolonialne sile $\mathrm{v}$ domači politični, družbeni in kulturni red odigra ključno, a izrazito ambivalentno vlogo posrednika med »ljudstvom Sobe« oziroma njegovim vladarjem ter francoskimi zavojevalci. Skozi ta lik je Kourouma izrecno tematiziral problem medkulturnega/medjezikovnega dialoga, ki se vedno znova spotakne ob razpoko med različnimi kodi udeležencev $\mathrm{v}$ komunikaciji, pa tudi možnosti strateške manipulacije s takšnimi nesporazumi:

»Za [kraljevo] odločitvijo, da preneha s poukom [francoščine], so stali resnejši politični in verski razlogi. Bolje kot kdorkoli je poznal samovoljo poveljnikov. $S$ tem, da je med sabo in belcem obdržal tolmača, si je zagotovil razdaljo, nekaj svoboščin, čas za razmislek, možnosti za oklevanja in pripombe; ohranjal je določeno nerazumevanje.« (Kourouma, 1990, 226)

Še več, daleč od tega, da bi bilo prevajanje nedolžno »medkulturno posredovanje«, je tudi posredovanje med nesimetričnimi pozicijami moči in interesa ter ima zato neogibno politični naboj. Kouroumovo opozorilo, za 
kako kočljiv proces pravzaprav gre, je zato odlično izhodišče za razmislek o prevajanju afriških evrofonskih književnosti v druge evropske jezike.

\section{Afriške književnosti v evropskih jezikih}

Ni mogoče mimo dejstva, da so to eksogeni jeziki, ki so se v tem prostoru uveljavili s kolonizacijo, ki ohranjajo svoj status dominantnih oziroma elitnih jezikov (z eksogeno, evropsko normo), govori (kaj šele bere) pa jih manjšina prebivalstva. Po drugi strani se v praksi razvijajo lokalne, nestandardizirane/podstandardne različice teh jezikov, ki v urbanih območjih postajajo nova orodja širokega sporazumevanja (na primer nigerijski pidžin, kamfrangleščina, abidžanska francoščina) in se torej umeščajo tudi v nedominantne (ne pa povsem marginalne) lege lokalnih heteroglosij. Položaj je torej močno drugačen od položaja evropskih nacionalnih jezikov, pri katerih obstaja impliciten enačaj med nacionalnim in maternim jezikom, $\mathrm{v}$ literaturi pa še tiha domneva o naravnosti oziroma samoumevnosti pisanja v maternem jeziku.

Ko govorimo o afriških (in tudi nekaterih drugih nezahodnih) književnostih v evropskih jezikih, moramo imeti pred očmi, kakšne možnosti imajo pisatelji na voljo za svoje strateško umeščanje v te jezike oziroma za njihovo prilaščanje. Na deklarativni ravni najdemo celo lestvico umeščanj, od slavne izjave kongovskega pesnika in pisatelja Tchicaye U Tam'sija: »francoski jezik me kolonizira in jaz ga koloniziram nazaj« (v: Gauvin, 41) prek strateške naturalizacije evropskega jezika pri Abdourahmanu A. Waberiju (»francoski jezik in literaturo poznam že od šolske zibke, če lahko tako rečem «, v: Martin in Drevet, 107) pa do stališča, ki ga zrcali izjava Kossija Efouija: »Mislim, da je kateri koli jezik ustrezen. Vse je odvisno od tega, kako ga obravnavaš [...] kajti izhodišče pisanja je nezaupanje do katerega koli jezika, vključno z lastnim. « (nav. d., 127) Na ravni besedil je položaj še bolj zapleten, ambivalenten in pogosto protisloven, in sicer zaradi divergentnih bralskih obzorij, med katerimi križari (ali s priljubljeno metaforo iz postkolonialnih študij: baranta) besedilo. Besedila, ki dramatizira svojo umestitev na meji oziroma $\mathrm{v}$ dinamičnem vmesnem prostoru, $\mathrm{v}$ prevodu 
preprosto ni mogoče zvesti na referenčni sistem ene ciljne kulture, ne da bi pri tem izgubilo velik del svoje specifične pomenljivosti.

Poleg tega pri evrofonskih afriških književnostih večinoma ne moremo predpostavljati identitete med jezikom pisanja in jezikom (jeziki) družbene realnosti, na katero se to pisanje nanaša. Zato je na delu kompleksno posredovanje med izvornim kontekstom in jezikom izvirnika ter soočanje $\mathrm{z}$ jezikovnimi praksami, reprezentacijami in normami, vpeto $\mathrm{v}$ simbolna in politična razmerja moči. In močnejše ko so politične implikacije jezikovnih strategij danega besedila, močnejši politični naboj zadobijo prevodne izbire. Problematiki razmerij moči se prevod preprosto ne more izogniti, zato se ji tudi prevodna refleksija ne bi smela, še toliko manj pa v močno polariziranih in zapletenih kontekstih, kakršni so tudi (a ne samo) postkolonialni. ${ }^{1}$

Oglejmo si nekaj radikalnejših primerov takšnega posredovanja, kjer se kulturna politika besedil zelo očitno odigrava na ravni uporabe in obdelave jezika. Pri tem se bom naslanjala na Bahtinovo stilistiko romana, saj prav Bahtinov pristop k jeziku kot dinamični mreži družbenih jezikovnih praks in k romanu kot hibridnemu žanru, katerega nastanek pogojuje zavest o drugih jezikih in kulturah, ponuja odlično izhodišče za analizo besedil, ki se ne umeščajo v klasične nacionalne literarne kontekste »zahodnega « tipa. Pomembna implikacija Bahtinove misli je, da roman $n i$ definiran kot $\mathrm{v}$ osnovi evropski žanr (kar mimogrede elegantno razreši sporno vprašanje 0 "avtentičnosti « in primernosti tega žanra za izvenevropske kontekste, vključno $\mathrm{z}$ afriškimi, ter težišče pozornosti premakne s problematike prisvajanja žanra k pogojem, $\mathrm{v}$ katerih se je lahko razmahnil $\mathrm{v}$ teh drugih prostorih); o njeni relevantnosti za postkolonialne kontekste zanimivo pričajo tudi številna sovpadanja z mislijo martiniškega pisatelja, pesnika in filozofa Edouarda Glissanta. ${ }^{2}$

1.1 Bahtinova stilistika romana temelji na podmeni, da slog romana leži v specifični konfiguraciji umetniških podob družbenih jezikov, orkestraciji družbenega večjezičja. Izraz »orkestracija« se nanaša na različne tipe sopri-

1 Splošneje o tem glej tudi Zakrajšek, K.: Potujitveni in prisvajajoči prevod v luči medjezikovnih razmerij moči, v: Hieronymus (ur. Ožbot, M.), v pripravi.

2 Prim. tudi Zakrajšek (2007b). 
sotnosti družbenih glasov in perspektiv v besedilu (kadar jih ne potlači monologizirajoča gesta); in ti so pravzaprav pravi protagonisti romana, vključeni v poseben tip dialoga, ki se odvija v vmesnih prostorih dvoglasne besede, ki je ni mogoče razstaviti na ločene replike kot pri dramskem dialogu.

Izraz "podoba jezika « pa se nanaša na način, kako je določen družbeni jezik - narečje, register, jezik nekega literarnega obdobja itd. - predstavljen v romanu: kako ta predeluje in stilizira predobstoječe diskurze. Res je, da je Bahtin svojo teorijo razvijal ob korpusu "velikih" evropskih romanov, vendar pa je njen poudarek na zavedanju drugih glasov (glasov drugih) in drugih perspektiv, z vsemi etičnimi in političnimi implikacijami, zaradi česar je nadvse uporabna v obrobnih, mejnih, pluralnih ... kontekstih, v kakršnih se razvijajo afriške literature v evropskih jezikih. Pomembno pri tem konceptu je, da ne privilegira osrednje norme, ki je razumljena kot le še en družbeni diskurz, ampak omogoča opis vsake (lokalne) heteroglosije v njeni mnogoterosti - pa naj gre za položaje, kjer je v igri več jezikov, ali pa za takšne, ki se omejujejo na en »nacionalni« jezik. Koncepta podobe in stilizacije premestita središče pozornosti z vprašanj "pravilnosti« in »zvestobe« ali »avtentičnosti« (se v nigerijskem pidžinu res reče tako?) na učinkovitost (je to prepričljiva in sugestivna reprezentacija nigerijskega pidžina?). ${ }^{3}$

Podoba jezika v romanu je po Bahtinu vedno dialoška in dvoglasna, pomeni stik in izmenjavo med vsaj dvema družbenima jezikoma, ki se lahko soočata na različne načine: prvine enega se lahko vtkejo $\mathrm{v}$ drugega $\mathrm{v}$ isti skladenjski enoti, tako da nastane hibridna izjava, ali pa predstavljajoči glas v dejanju predstavljanja vrednostno naglasi predstavljeni družbeni diskurz - ga poda afirmativno, ironično, parodično itd. Kar je pomembno, je, da med temi implicitnimi vrednotenji ni ostrih ločnic: dvoglasna beseda je po definiciji torišče ambivalence, ki jo omogoča distanca, porojena iz zavesti, da je jezik prenapolnjen $\mathrm{z}$ divergentnimi in nasprotujočimi si diskurzi.

3 Prakse izven standardnih jezikov in v kontaktnih območjih med njimi praviloma nimajo pisne oblike, gotovo pa ne stabilizirane pisne oblike. Vključevanje teh obrobnih družbenih jezikov $\mathrm{v}$ pisno literaturo je zato vedno prav toliko tehnično kot kulturnopolitično vprašanje: $v$ praksi je pisatelj postavljen pred zahtevo (sorazmerne) berljivosti - vendar pa se številni avtorji energično upirajo temu, da bi ustvarili (iluzorno) transparentno besedilo (transparentno za katerega bralca?); prim. Nganangove ironične opombe v obravnavanem romanu. 
1.2 Prav v primeru nestandardnih jezikovnih praks, kot so lokalne različice bivših kolonialnih jezikov v Afriki (urbana francoščina ...) ter kreolski in pidžinski jeziki, ki so izšli iz njih - oboji so vedno bolj prisotni v književnosti -, je koncept podobe jezika še zlasti koristen. Pozornost namreč usmerja na to, kako besedilo sugerira te prakse, ne pa, kako jih »transponira« v standardni pisni kod. Primeren je denimo za literarna sklicevanja na »ljudske» različice (bivših) imperialnih jezikov, pa tudi na nestabilizirane kontaktne jezike (kreolske jezike in pidžine). Tako na primer roman kamerunskega pisatelja Patricea Ngananga Temps de chien vključuje reprezentacije ljudske yaoundejske francoščine in kamfrangleščine $\mathrm{v}$ besedilo, v katerem francoski jezik služi kot nevtralna matrica za sporazumevanje znotraj širšega afriškega konteksta. Leta 2001 je ta francoščina že izpraznjena referenc na nekdanji kolonialni center in redefinirana kot afriški jezik: poanta, ki jo podčrtujejo Nganangove ironične opombe pod črto v prvi izdaji, kjer je na zahtevo urednika prevedel stavke $\mathrm{v}$ kamfrangleščini - pa ne v standardno evropsko francoščino, ampak v urbano afriško francoščino. Tako je na primer stavek »If he no fit tchop he moni, n'est-ce pas la mbok-là va l'aider? «v opombi preveden kot »S'il ne pouvait pas manger son argent, n'est-ce pas la pute-là va l'y aider? « ( $v$ : Lefebvre, 41$)$. Podobno tudi roman nigerijskega pisatelja Kena Saro-Wiwe Soldatko (Sozaboy) črpa iz nigerijske pidžinske angleščine, da bi podal izkušnjo in mentalni zemljevid prvoosebnega pripovedovalca. Seveda pidžin, ki je bil leta 1985 še omejen skorajda izključno na ustno rabo, ni vključen v »surovem « stanju, v svoji "pristni« obliki; uporabo $\mathrm{v}$ pisnem mediju spremlja tudi pragmatično motiviran premik proti visokemu registru diglosije med pidžinom in standardno angleščino. Cilj teh premikov je ustvariti učinkovito reprezentacijo pidžinske angleščine $\mathrm{v}$ mediju mednarodne angleščine (ki za anglofonskega bralca pomeni horizont berljivosti):

"Radio begin dey hala as 'e never hala before. Big big grammar. Long long words (...) As grammar plenty, na so trouble plenty.« (Saro-Wiwa, 1994, 3)

Zanimivo je, da ta delna izravnava jezikovne razlike $\mathrm{v}$ diglosiji ne zabriše njenih učinkov: nasprotno, to je strategija izognitve prevajanju kot 
»zvajanju « pidžina na standardno angleščino (ki bi dejansko izbrisalo družbeno razliko in marginalnega »drugega " napravilo transparentnega $\mathrm{v}$ standardnem jeziku), s tem pa diglosija in njen družbeni pomen šele postaneta očitna za »zunanje« bralce; ti pa se morajo tudi potruditi, da razvozlajo vpletene družbene jezike in njihova razmerja. V Soldatku se razmerje med glasovi, ki tvorijo hibridni diskurz pripovedi, nenehoma spreminja, kar omogoča, da pripoved podčrtuje zdaj soldatkovo naivnost zdaj njegovo lucidnost ter ustvarja kompleksno podobo tega »substandardnega«, deprivilegiranega »objekta« zgodovine.

1.3 Koncept podobe jezika je koristen tudi v primerih - precej pogostih zlasti v starejših afriških književnostih -, kjer je en jezik s svojo kulturo izpisan v drugem, dominantnem jeziku, ki ni del njegove jezikovne realnosti. V tem primeru je koristno razlikovati med izhodiščnim jezikom in jezikom izvirnika. Nekateri avtorji so se $\mathrm{v}$ teh okoliščinah zatekali k obsežnemu kalkiranju skladenjskih struktur in (pogosteje) določenih govornih žanrov (od pozdravov do pregovorov itd.). Izid je že preveden izvirnik, kjer so v jeziku, v katerem je napisan, prisotni palimpsestni sledovi izhodiščnega jezika. Med najbolj znanimi primeri je roman Les soleils des indépendances Ahmadouja Kouroume, ki je napisan v francoščini (jezik izvirnika), medtem ko je jezik tako njegovih protagonistov in (vsaj delno) tudi pripovedovalca $\mathrm{v}$ resnici maninka (izhodiščni jezik). Tu dvoglasna bahtinovska hibridna beseda postane triglasna, saj se v njej francoščina kot (literarni) jezik nalaga na spremenljivo prepletanje maninških glasov pripovedovalca in protagonistov:

»Là, entre les toits, apparaissaient divers cieux: le tourmenté par les vents qui arrachaient des nuages pour les jeter sur le soleil déjà couvert et éteint, le bas épais et indigo montant de la mer et avançant sur les maisons et les arbres inquiets et tremblotants. Lorage était proche. Ville sale et gluante de pluies ! pourrie de pluies!« (Kourouma, 1970, 21)

Tu lahko morfosintaktične posebnosti ( $\mathrm{v}$ tem navedku na primer za francoščino nenavadno posamostaljenje pridevnikov »le tourmenté«, »le 
bas«) pripišemo pripovedovalčevemu diskurzu v maninki, ${ }^{4} \mathrm{v}$ zadnjem stavku (»Ville sale ...«) pa v obsodbi mesta ob pripovedovalčevi sozazveni tudi beseda glavnega junaka. Roman Nigerijca Gabriela Okare The Voice na podoben način uporabi angleščino, da skoznjo predstavi jezik idžo ter zanj značilne miselne in jezikovne vzorce. Oba pisatelja sta si kot koloniziranca vzela pravico, da sta si prilastila dominantni jezik, ga razstavila in reorganizirala ter iz njega naredila orodje za predstavljanje prav tistih kulturnih diskurzov, ki jih je kot kolonialni jezik dušil ali izbrisoval. Podoba koloniziranega jezika $\mathrm{v}$ kolonialnem (ali širše, dominiranega $\mathrm{v}$ dominantnem), kolonizirani jezik, ki si podredi besedilo v kolonialnem jeziku - pa ne le v dialogu, kar bi lahko učinkovalo le kot element lokalnega kolorita, temveč prav v pripovedovalčevem besedilu, kot se zgodi v omenjenih romanih ima močan politični naboj, neločljiv od prav tako močnih estetskih učinkov. Zanimivo je, da so Kouroumo nekateri od njegovih afriških vrstnikov sprva celo obtoževali »slabe francoščine«.

1.4 Spet drugi pisatelji v drugojezično izvirno besedilo vpletejo neprevedene besede in izraze $\mathrm{v}$ izhodiščnem jeziku, ki jih včasih prevedejo ali razložijo $\mathrm{v}$ samem besedilu ali $\mathrm{v}$ opombah pod črto ( $\mathrm{v}$ starejših tekstih je to prevladujoča rešitev) oziroma prepustijo bralcu, da njihov pomen izlušči iz konteksta. ${ }^{5}$ Te neprevedene izraze številni razumejo kot nekakšne simbolne zastopnike temeljne kulture, koncentrat njenih najpomembnejših vidikov. Vendar jih je plodneje brati kot metonime, kot občasne opomine o kulturni razliki, ki strukturira besedilo, ki je pogosto napisano v standardnem ali celo privzdignjenem registru drugega jezika, kot je vidno v naslednjem primeru iz romana Létrange destin de Wangrin malijskega pisatelja Amadouja Hampatéja Bâja (za ilustracijo so v navedku ohranjene oznake opomb - te so zbrane na koncu romana in vsebujejo prevode, pa tudi obširnejše etnološke komentarje -, neprevedene besede iz izhodiščnega jezika pa so podčrtane):

4 O preoblikovanju francoščine pod vplivom maninke v tem Kouroumovem romanu prim. zlasti Gassama (za analizo konkretnih primerov; 1995), pa tudi Moro (2002) in Borgomano (1998).

5 Prim. Zabus (1990). 
»Bamuso (64)! lui cria-t-elle. Dutigui (65) est faché! Il a jeté sur moi un regard plus sombre qu'une nuit de tornade et d’orage ...« (Hampaté Bâ, 1992, 99)

Tretjič, koncept podobe jezika je uporaben $\mathrm{v}$ analizi literarnih del, ki morajo "sploščiti« radikalno večjezično realnost na pretežno enojezično površino besedila, kar je zelo pogosto zlasti v tistih afriških romanih, ki so postavljeni v urbano okolje. Dober primer je zgoraj omenjeni Létrange destin de Wangrin, kjer so v besedilu, ki je z izjemo nekaj (prečrkovanih) izposojenk napisano $\mathrm{v}$ francoščini, reprezentirani standardna francoščina, français tirailleur (tako imenovana, ker se je izoblikovala kot lingva franka kolonialne vojske) in več avtohtonih zahodnoafriških jezikov. Med jezikovno najzanimivejšimi vidiki tega romana je privzdignjena dikcija, pogosto navdahnjena $\mathrm{z}$ retoriko francoske klasicistične literature, ki je uporabljena $\mathrm{v}$ določenih dialogih med govorci afriških jezikov:

»Ô ma sœur Rammaye, je me retiens pour te plaire, mais apprends que l'amour est comme un fleuve. Son eau roule, sécoule et passe, mais jamais il ne tarit ni ne varie d’état.« (Hampaté Bâ, 1992, 127)

Ta visoki register francoščine, križan s podobjem in retoriko zahodnoafriških jezikov, evropskemu bralcu zazveni hkrati domače in radikalno tuje. Implikacija dominantne kulture in elitne tradicije, ki jo nosi, je subverzivno uporabljena za reprezentiranje zanikane rafiniranosti marginalizirane kulture: to transgresivno prilaščanje in razlaščanje dominantnega jezika prinaša pomenljiv zasuk pozicij moči in vrednosti, saj je govor francoskih likov v romanu predstavljen z mnogo bolj vsakdanjim jezikom. Podoben primer takšne namerne "poneverbe « registrov dominantnega jezika in njihovih implikacij v literarnem sistemu, iz katerega izvira, za predstavljanje rafiniranosti in kompleksnosti dominirane kulture je roman Aventure ambigüe senegalskega pisatelja Cheikha Amidouja Kana.

1.5 Dotaknimo se še Bahtinovega razumevanja jezika kot »tujega«, kot »besede drugega«: človek usvoji jezik skozi proces socializacije (in v tej luči 
je materni jezik preprosto prvi tuji jezik, ki se ga nauči); poleg tega ga ne usvoji kot abstrakten sistem, ampak tako, da vstopa v niz jezikovnih praks glede na svoj položaj in življenjsko pot $\mathrm{v}$ dani jezikovni skupnosti, ki je vedno heterogena in heteroglotna. To tujo besedo si lahko polno prisvoji le tako, da jo ustvarjalno uporablja in spreminja (torej sodeluje v njenem razvoju). Ta razmislek je še posebej pomemben, kadar imamo opraviti s kočljivim vprašanjem prisvajanja (nekdanjih) kolonialnih jezikov, tako v literaturi kot zunaj nje, saj podpira dekonstrukcijo iz romantike podedovanega miselnega avtomatizma, po katerem je edino naravno in pristno pisati v maternem jeziku (in po katerem so torej drugojezične književnosti nekako »drugotne«). Številni postkolonialni pisatelji dejansko trdijo, da ti jeziki zdaj pripadajo tudi njim in jih imajo pravico uporabljati za lastne namene. Navedli smo že U Tam'sijevo krilatico, ki jedrnato povzema proces vzvratne kolonizacije. Ko si drugi prisvoji jezik, ki ga drugači, in ga uporabi po svoje, s tem zavrne zahtevo metropole po središčnem položaju, bralca iz nekdanjega imperialnega centra odrine na položaj outsiderja in mu v številnih primerih $\mathrm{z}$ uporabo strategij namerne neprosojnosti ${ }^{6}$ celo otežuje dostop do besedila. Pri takšni analizi ne gre za izraz posameznika, ki korenini v polnem, prvinskem stiku z maternim jezikom (mimo njegovih družbenih dimenzij), ampak za kreativno spopadanje $\mathrm{z}$ družbenim večjezičjem danega kulturnega konteksta in za njegovo umetniško predstavitev s pomočjo razpoložljivih jezikovnih sredstev ali celo v spopadu z njimi (pri subverzivnih rabah dominantnih jezikov kot v Kouroumovih Les soleils).

\section{Nekaj možnih prevajalskih pristopov}

Sledeč tej bahtinovski analizi se na tej točki zastavi vprašanje, kako naj prevod v ciljnem jeziku in glede na možnosti, ki jih ta ponuja, predstavi izhodiščno besedilo $\mathrm{z}$ njegovo orkestracijo podob jezika, način, kako to besedilo obravnava družbeno večjezičje - skratka, njegovo jezikovno in kulturno politiko. To je seveda načelno vprašanje, ki ne zadeva le prevajanja afriških književnosti. Specifičen izziv, ki ga praviloma zastavljajo afriški

6 Za analizo konkretnega primera glej Caron (1998). 
evrofonski romani kot razsrediščena besedila, ki kažejo v več smeri naenkrat in se nanašajo na več sistemov kulturnih referenc ter tako omogočajo različne načine vstopa $\mathrm{v}$ tekst in različnim občinstvom ponujajo različne vidike »normalnosti« in »normativnosti«, je, da rešitve ni mogoče zajeti v običajni okvir ciljnega (nacionalnega) jezika. Le redko je v tem mogoče najti tesno vzporedno konfiguracijo družbenih jezikov, ki jo je mogoče aktivirati $\mathrm{v}$ prevodu in tako reaktualizirati kulturno politiko teksta $\mathrm{v}$ ciljnem (super)sistemu - kot se je zgodilo v francoskem prevodu Soldatka, kjer je izbira abidžanske francoščine kot ustreznice nigerijskega pidžina utemeljena na primerljivi sociologiji teh dveh jezikov in njunem razmerju s standardno dominantno različico. Drugi jeziki, med katerimi je tudi slovenščina, nimajo takšnih že obstoječih plasti. Lahko pa prevajalec razišče polje možnega $\mathrm{v}$ ciljnem jeziku in ga preoblikuje (razširi), da zmore predstaviti razliko oziroma večjezičje, ki strukturira izhodiščno besedilo, njegove družbene implikacije in njegovo specifično umetniško obdelavo $\mathrm{v}$ izhodiščnem besedilu.

2.1 Pri prevajanju Kouroumovega romana Alahu ni treba, kjer so napetosti med afriško francoščino in njeno evropsko normo celo izrecno tematizirane, sem bila torej prisiljena h konstruiranju umetne "afrikanizirane slovenščine, da bi predstavila to plast besedila. ${ }^{7}$ Nekaj let pozneje je ob Saro-Wiwovem Soldatku podobno strategijo, a v mnogo širšem obsegu, ubral Andrej Skubic, ki je konstruiral osupljivo prevodno podobo Saro-Wiwove »avtorske« podobe nigerijskega pidžina ter dokazal, da lahko tak konstrukt »zdrži« skozi celoten roman. Pri tem je upošteval procese nastajanja pidžinskih in kreolskih jezikov, kjer se, $v$ grobem rečeno, na osnovi prvotne poenostavljene slovnice in omejenega besedišča oblikuje nov kompleksen jezik, ko govorci to gradivo razvijajo glede na svoje komunikacijske potrebe: prav zavest o tem je bistvena, če naj podoba besede drugega ne zapade v tarzanske klišeje ali klišeje »črnskega (ali nasploh »divjaškega «) jezika iz starih pustolovskih knjig. Velika nevarnost takih poskusov je infantilizacija pripovedovalca (Skubic, 2008, 10). Tako konstruirana podoba podobe dominiranega jezika $\mathrm{v}$ dominantnem nosi kompleksno pripoved, ki je or-

7 Za podrobnejšo analizo tega primera prim. Zakrajšek (2004). 
ganizirana okrog izkušnje utišanega "predmeta« zgodovine: povedati jo v standardnem jeziku bi pomenilo povedati jo s stališča zmagovalca.

2.2 Palimpsestno prisotne že prevedene besedilne prvine ali celotna besedila, kjer med jezikom izvirnika in izhodiščnim jezikom $\mathrm{v}$ nasprotju $\mathrm{s}$ prejšnjim primerom ni genetske povezave in drugi ni marginalna, dominirana različica prvega - omenili smo že Kouroumove Les soleils des indépendances in Okarov The Voice -, zahtevajo drugačen pristop. Po svoje je tu lažje razbrati transformacije jezika izvirnika, ki nastanejo pod vplivom izhodiščnega jezika in katerih rezultat je upodobitev tega jezika $\mathrm{z}$ gradivom drugega. V prevodu je mogoče vsaj do neke mere uvesti enakovrstne transformacije, čeprav gre v praksi za sklepanje na podlagi avtorjeve obdelave jezika izvirnika in ne na podlagi prevajalčevega poznavanja izhodiščnega jezika, kar bi bilo sicer idealno. Prav kot pisatelj v takšnem primeru iz jezika, v katerem piše, izžene njegove »lastnike«, da v njem odpre prostor za glasove, ki niso v njem nikoli spregovorili (in ki jih je ta jezik utišal), naj bi tudi prevajalec ciljni jezik razprl onkraj trenutnega razpona večjezičja in ga odprl za druge možnosti dialoškega odnosa z drugim(i), ne da bi ga (jih) zvajal na standarde ciljne kulture. ${ }^{8}$ Zanimivo je, da slovenščina zastavlja tudi specifično težavo za takšno prevodno strategijo, namreč veliko gibkost v skladnji, ki dovoljuje kar najrazličnejše načine organizacije povedi - zato

8 Zanimiv primer nasprotnega ravnanja je Queneaujev prisvajajoči prevod dela The Palm-Wine Drinkard nigerijskega pisatelja Amosa Tutuole. Zgovorna je že primerjava prvega stavka Tutuolovega izvirnika, za katerega je značilna ustvarjalna, a povsem »nepravilna« raba angleščine, in Queneaujevega tekočega prevoda $v$ standardni francoščini:

"I was a palm-wine drinkard since I was a boy of ten years of age. I had no work more than to drink palm-wine in my life« (Tutola, 1952, 1).

"Je me soûlais au vin de palme depuis l'âge de 10 ans. Je n'avais rien eu d'autre à faire dans la vie que de boire du vin de palme« (Tutuola, 2006, 1).

Morda je Queneauja tako pritegnila zgodba, ki je v njegovem francoskem kontekstu delovala nadrealistično, ter Tutuolove (nenamerne) kršitve zahodnih narativnih konvencij (pravzaprav ni pisal proti njim, ampak mimo njih), da sploh ni opazil, kako avtorjeva jorubščina preoblikuje površino besedila, ali pa se mu to ni zdelo pomembno. (Ta primer je še toliko bolj zapleten zaradi vprašanja, kakšno vlogo pripisati avtorski nameri, saj je sodeč po razpoložljivih virih le malo izobraženi, a izjemno ustvarjalni Tutuola preprosto pisal v najboljši angleščini, ki jo je premogel, pri tem pa mimogrede, a nenamerno, vanjo vpisal jorubščino in dosegel podoben učinek kot nekateri drugi avtorji, pri katerih je šlo za zavestno strategijo.) 
bi bilo v nekaterih primerih težje doseči učinek tujosti, drugosti, ki izvira iz trka med skladnjo izhodiščnega jezika in jezika izvirnika, zlasti kadar gre za vprašanja besednega reda. Vendarle pa z bivšimi kolonialnimi jeziki v zadostni meri deli jezikovno logiko, da bi marsikakšna skladenjska transformacija tudi v slovenskem prevodu zazvenela zelo tuje - kot v naslednjem primeru:

»Who are you people be?« Okolo asked. The people opened not their mouths. »If you are coming-in people be, then come in«. (Okara, 1970, 26)

Najtrši oreh je tu predstavitev elementa, ki je $\mathrm{v}$ angleščini podan kot »be«, saj je povsem tuj logiki označevanja glagolskega dejanja v indoevropskih jezikih; vendarle pa je tako radikalna transformacija jezika pisanja, ki $\mathrm{v}$ tem primeru zadeva tudi samo morfologijo, zelo redka in pomeni mejni primer prevedljivosti.

Lažje izvedljiva (in zato pogosteje udejanjena) je ta strategija pri prevajanju metaforike, pregovorov, pozdravov itd. - torej posameznih že prevedenih besedilnih elementov, kar je tudi pogostejša možnost palimpsestnega vključevanja izhodiščnega jezika $\mathrm{v}$ drugojezično izvirno besedilo. Kouroumova Les soleils des indépendances nudijo mnogo takšnih primerov, pogosto v povezavi s skladenjskimi transformacijami. Prvi stavek se glasi:

"Il y avait une semaine qu’avait fini dans la capitale Koné Ibrahima, de race malinké, ou disons-le en malinké: il n’avait pas soutenu un petit rhume ..." (Kourouma, 1970, 9)

Tu je lahko zelo uspešen kar dobeseden prevod, s pridržkom, da je treba to »dobesednost « pridržati za elemente, v katerih vidimo posledico učinkovanja izhodiščnega jezika na jezik literarnega izvirnika - v danem primeru torej ne bi bilo primerno od besede do besede prevajati standardno francoskega »il y avait «, temveč izraz »avoir fini« za »umreti« ter seveda navedeni rek; z zavestnim ohranjanjem iste »neregularne« strukture informacij v stavku bi se prevod lahko glasil: 
„Pred tednom dni je končal v prestolnici Koné Ibrahima, Maninka po rodu, ali recimo po maninško: podlegel je majhnemu prehladu ..."

Kadar izhodiščni jezik ne preoblikuje slovnične strukture jezika pisanja, ampak so vanj vpletene posamezne neprevedene besede in izrazi, se vprašanje njegove obravnave v prevodu zastavlja drugače. Pogosto - v afriških literaturah kar praviloma - so te besede in izrazi podani v približni fonetični transliteraciji, dostikrat tudi zato, ker izhodiščni jezik ni (še ni bil) zapisan, danes pa morda tudi iz navade ali iz konvencije. Kakorkoli, če bi ta prečrkovanja povzeli v prevedenem besedilu, bi to pomenilo »kolonizacijo « tako izhodiščne kot ciljne kulture in njuno podrejanje standardom izvirnega jezika (če pustimo ob strani, da takšne transliteracije ciljnemu bralcu ne koristijo). Načeloma je izhodiščni jezik mogoče predstaviti z uporabo njegovega lastnega pravopisa (kadar ta obstaja); alternativna možnost (tudi glede na namen in ciljno publiko prevoda) je fonetična transliteracija $\mathrm{v}$ ciljnem jeziku, vsekakor pa $\mathrm{v}$ njegovi prevodni podobi ni mesta za jezik izvirnika. Tako na primer v slovenskem prevodu Razpada Chinue Achebeja povsem smiselno beremo slovensko prečrkovane citatne besede, kot je na primer »ndiči« (v angleškem izvirniku zapisano kot »ndichi«), kar bralcu vsaj posreduje informacijo o njihovem približnem izgovoru.

\section{Sklep: k politiki neasimilativnega prevoda}

Afriške književnosti torej zastavljajo vrsto prevodnih izzivov, katerih reševanje zahteva izstop iz konceptualnih okvirov nacionalnega jezika in nacionalne literature, kot sem poskusila nakazati z uporabo Bahtinovih konceptov podobe jezika in orkestracije večjezičja. Lahko rečemo, da je uspešen prevod afriškega besedila tisti, ki upošteva specifično kulturno (in kulturnopolitično) umestitev besedila ter jo postavlja pred bralca prevoda, tako da ne prevaja le posameznih slogovnih prvin, ampak v prevodu rekonstruira njihova medsebojna razmerja, pri čemer lahko tudi identificira in dramatizira monologizirajoče silnice, lastne ciljnemu jeziku, ter aktualizira 
v njem prisotne diskurze o drugem/drugih. Pomemben element takšnega neasimilativnega prevoda je tudi paratekstualni aparat: opombe (čeprav so te, če jih je preveč, lahko moteče), prevajalčev predgovor in/ali spremno besedilo, ki bralcu ponudi ozadje, pojasni kulturno umestitev besedila in politični ter jezikovni kontekst, $\mathrm{v}$ katerem je nastalo.

To pa pomeni, da je pogosta zahteva, naj bo prevod transparenten, naj izgine kot prevod, tako da ustvari iluzijo neposrednega dostopa k izvirnemu besedilu, izjemno problematična, še toliko bolj $\mathrm{v}$ postkolonialnih kontekstih in pri postkolonialnih tekstih, ki dramatizirajo lastno specifično zgodovinsko umeščenost. Odgovoren prevod takšnih besedil se tej iluziji izogiba. Priznanje lastnega statusa kot prevoda mu ne preprečuje, da bi bil odlično literarno delo; konec koncev sta, kot sem argumentirala zgoraj, tako »izvirnik« kot prevod konfiguraciji podob jezikov (ki so lahko bolj ali manj oddaljeni od jezika pisanja/prevoda). Lahko pa ga obvaruje pred nevarnostjo sodelovanja $\mathrm{v}$ preoblačenju etnocentričnih predpostavk $\mathrm{v}$ diskurz univerzalnosti in transparentnosti, $\mathrm{v}$ katerem se izgubi pomen specifične (med)kulturne lokacije in izkušnje.

Takšen prevod pritrjuje in udejanja pravico drugega do neprosojnosti. Ne posreduje prek meja med kulturnimi esencami, ampak med pluralnimi, spremenljivimi, hibridnimi kulturnimi lokacijami. To zahteva določen trud tako s strani prevajalca - prevpraševanje obrobij jezikov, ne le njunih standardiziranih in standardizirajočih središč - kot bralca, ki je prisiljen dejavno pristopiti k pišočemu in izpisanemu drugemu ter v razumevanje vložiti nekaj napora, ne le vnesti že izdelanih predpostavk. S tem pa prevod, ki ga bom zasilno poimenovala "postkolonialen«, dovrši svoj lasten dvoglasni umetniški, etični in kulturnopolitični projekt. 


\section{VIRI IN LITERATURA}

1.

Bâ, A. H., Létrange destin de Wangrin, Pariz 1992.

Kane, Ch. K., Aventure ambigüe, Pariz 2002.

Kourouma, A., Les soleils des indépendances, Pariz 1970.

Kourouma, A., Monnè, outrages et défis, Pariz 1990.

Kourouma, A., Allah n'est pas obligé, Pariz 2000.

Kourouma, A., Alahu ni treba, Ljubljana 2004.

Nganang, P., Temps de chien, Pariz 2003.

Okara, G., The Voice, London 1970.

Saro-Wiwa, K., Sozaboy, London 1994.

Saro-Wiwa, K., Sozaboy: Pétit minitaire, Pariz 1998.

Saro-Wiwa, K., Sozaboy, Ljubljana 2008.

Tutuola, A., The Palm-Wine Drinkard, London 1952.

Tutuola, A., L'ivrogne dans la brousse, Pariz 2006.

2.

Appiah, K. A., Thick translation, v: The translation studies reader (ur. Venuti, L.), London in New York 2000, str. 417-429.

Bahtin, M., The dialogic imagination, Austin 1981.

Bahtin, M., Teorija romana: izbrane razprave, Ljubljana 1982.

Bahtin, M., Problems of Dostoevsky's poetics, Minneappolis in London 2003.

Bhabha, H. K., The location of culture. London in New York 1994.

Borgomano, M., Ahmadou Kourouma: Le »guerrier« griot, Pariz 1998.

Caron, D., Pour une poétique de l'opacité: Ahmadou Kourouma, Édouard Glissant et l'espace de la Relation francophone, Canadian Review of Comparative Literature 3-4, 1998, str. 348-362. 
Cordonnier, J.-L., Traduction et culture, Pariz 1995.

Gassama, M., La Langue d' Ahmadou Kourouma ou le français sous le soleil d'Afrique, Pariz, 1995.

Gauvin, L., Lécrivain francophone à la croisée des langues: entretiens, Pariz 1997.

Lefebvre, A., Patrice Nganang et »la parole des sous-quartiers «: une approche sociolinguistique de lécriture du français dans le roman francophone, v: Discours et écritures dans les sociétés en mutation - Itinéraires et contacts de cultures 39 (ur. Bengoéchéa, M. in drugi), Pariz 2007, str. 35-47.

Martin, P. in Drevet, C., La langue française vue d’ailleurs, Casablanca 2001.

Moro, A., La langue de la communication interculturelle. Lexemple de Les soleils des indépendances et de Monnè, outrages et défis d'Ahmadou Kourouma, v: Littératures africaines: transpositions? (ur. Teulié, G.), Montpellier 2002, str. 355-368.

Skubic, A., Prevajalčev predgovor, v: Sozaboy (Saro-Wiwa, K.), Ljubljana 2008, str. 9-12.

Venuti, L., Translation, community, utopia, v: The translation studies reader (ur. Venuti, L.), London in New York 2000, str. 468-488.

Vevar, Š., Temeljni aspekti in principi literarnega prevajanja, Ljubljana 2000.

Zabus, C. Othering the foreign language in the West-African Europhone novel, Canadian Review of Comparative Literature 3-4, vol. 17, 1990, str. 348-366.

Zakrajšek, K., Kaj pa, ko pisatelj zapiše večjezično francoščino, v: Prevajanje besedil iz obdobja romantike: 29. prevajalski zbornik (ur. Ožbot, M.), Ljubljana 2004, str. 341-358.

Zakrajšek, K., Texte postcolonial et sa traduction. Discours et écritures dans les sociétés en mutation - Itinéraires et contacts de cultures 39 (ur. Bengoéchéa, M. in drugi), Pariz 2007(a), str. 181-193.

Zakrajšek, K., Postkolonialni dialogi, Primerjalna književnost 30/2, 2007(b), str. 19-34. 


\section{TRANSLATING THE AFRICAN EUROPHONE NOVEL INTO SLOVENIAN}

Keywords: African novel, translation, Bakhtin, postcolonial studies

\section{Abstract}

This article opens with a brief consideration of the implications of Europhone writing in Africa: writing in a second, ex-colonial and still dominant language, and divergence between the language of writing and the (often plural) linguistic reality of the society addressed by the text. Such writing implies complex mediation between the source context and the language of the original, a grappling with language practices, representations, and norms in symbolic and political power relations, meaning that the language strategies of the text have an unavoidable political charge. The same is true of translation choices.

The first part of the article analyzes some of the more radical textual strategies adopted by various African Europhone writers using a Bakhtinian approach, focusing on questions of language appropriation and literary representation of linguistic practices and, specifically, of social heteroglossia and its social and political implications in the postcolonial literary text in a European language. These strategies range from pidginization of the text (Ken Saro-Wiwa) to embedding untranslated material from indigenous languages (Amadou Hampâté Bâ) to syntactic and other transformations in which the language of writing is reorganized according to the patterns of an indigenous language, resulting in an already-translated original (Gabriel Okara, Ahmadou Kourouma).

The second part explores possible translation strategies in the light of this analysis, taking into account the position of Slovenian in relation to relevant ex-colonial and African languages. Depending on the situation, these strategies can include constructing a new virtual register for the target language (in order to represent the original image of a pidgin language), transforming target-language patterns to represent the transformations at work in an already-translated original, and adapting the transliteration of 
embedded untranslated material. The discussion is partly based on some translations into Slovenian that already exist.

The author argues for a translation approach based on consideration of the specific cultural and political location of each text as well as of the relative position of the source and target contexts and languages. Rather than a fluid, transparent translation that tends towards complicity in ethnocentric-masking-as-universal, the result of such strategies is a text that is explicitly a translation. Mediating between plural, shifting, and hybrid cultural locations, it reasserts the other's "right to opacity" and demands active participation on the part of the reader as well as the translator. In this way, what is provisionally termed "postcolonial translation" accomplishes its own, double-voiced artistic, ethical, cultural, and political project. 